\title{
Coronary artery calcium score prediction of all cause mortality and cardiovascular events in people with type 2 diabetes: systematic review and meta-analysis
}

Caroline K Kramer endocrinology research fellow ${ }^{12}$, Bernard Zinman professor of medicine ${ }^{123}$, Jorge L Gross professor of medicine ${ }^{4}$, Luis $\mathrm{H}$ Canani associate professor of medicine ${ }^{4}$, Ticiana $\mathrm{C}$ Rodrigues associate professor of medicine ${ }^{4}$, Mirela J Azevedo associate professor of medicine ${ }^{4}$, Ravi Retnakaran associate professor of medicine ${ }^{123}$

${ }^{1}$ Leadership Sinai Centre for Diabetes, Mount Sinai Hospital, 60 Murray Street, Suite L5-025, Mailbox-21, Toronto, ON, Canada M5T 3L9; ${ }^{2}$ Division of Endocrinology, University of Toronto, Toronto, Canada; ${ }^{3}$ Samuel Lunenfeld Research Institute, Mount Sinai Hospital; ${ }^{4}$ Division of Endocrinology, Hospital de Clínicas de Porto Alegre, Universidade Federal do Rio Grande do Sul, Porto Alegre, Brazil

\begin{abstract}
Objective To investigate the association of coronary artery calcium score with all cause mortality and cardiovascular events in people with type 2 diabetes.

Design Systematic review and meta-analysis of observational studies. Data sources Studies were identified from Embase, PubMed, and abstracts from the 2011 and 2012 annual meetings of the American Diabetes Association, European Association for the Study of Diabetes, American College of Cardiology, and American Heart Association (2011).

Eligibility criteria Prospective studies that evaluated baseline coronary artery calcium score in people with type 2 diabetes and subsequent all cause mortality or cardiovascular events (fatal and non-fatal).

Data extraction Two independent reviewers extracted the data. The predictive value of the coronary artery calcium score was assessed by random effects model.
\end{abstract}

Results Eight studies were included ( $\mathrm{n}=6521 ; 802$ events; mean follow-up 5.18 years). The relative risk for all cause mortality or cardiovascular events, or both comparing a total coronary artery calcium score of $\geq 10$ with a score of $<10$ was 5.47 (95\% confidence interval 2.59 to $\left.11.53 ; I^{2}=82.4 \%, P<0.001\right)$. The overall sensitivity of a total coronary artery calcium score of $\geq 10$ for this composite outcome was $94 \%$ (95\% confidence interval $89 \%$ to $96 \%$ ), with a specificity of $34 \%$ (24\% to $44 \%$ ). The positive and negative likelihood ratios were 1.41 (95\% confidence interval 1.20 to 1.66 ) and 0.18 (0.10 to 0.30$)$, respectively. For people with a coronary artery calcium score of $<10$, the post-test probability of the composite outcome was about $1.8 \%$, representing a 6.8 -fold reduction from the pretest probability. Four studies evaluated cardiovascular events as the outcome $(n=1805 ; 351$ events). The relative risk for cardiovascular events comparing a total coronary artery calcium score of $\geq 10$ with a score of $<10$ was 9.22 ( 2.73 to $\left.31.07 ; I^{2}=76.7 \%, P=0.005\right)$. The positive and negative likelihood ratios were 1.67 (1.30 to 2.17) and 0.11 (0.04 to 0.29$)$, respectively.

Correspondence to: R Retnakaran rretnakaran@mtsinai.on.ca

Video on bmj.com (see also http://bmj.com/video)

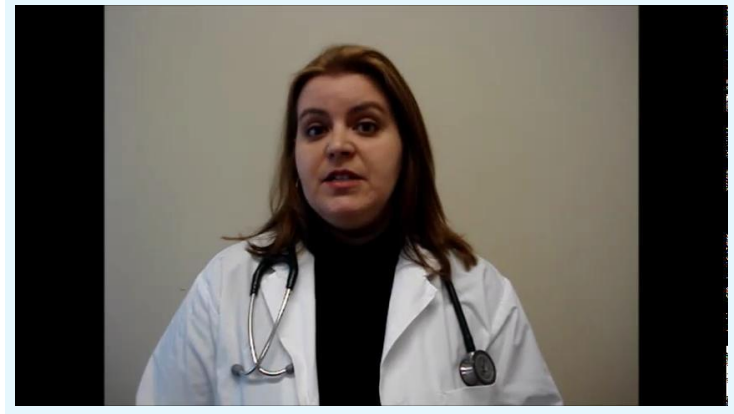


Conclusion In people with type 2 diabetes, a coronary artery calcium score of $\geq 10$ predicts all cause mortality or cardiovascular events, or both, and cardiovascular events alone, with high sensitivity but low specificity. Clinically, the finding of a coronary artery calcium score of $<10$ may facilitate risk stratification by enabling the identification of people at low risk within this high risk population.

\section{Introduction}

Cardiovascular disease is the major cause of morbidity and mortality in people with type 2 diabetes and the largest contributor to the direct and indirect costs of diabetes. ${ }^{1}$ Moreover, compared with people without diabetes, those with type 2 diabetes have a higher risk of mortality at comparable levels of coronary artery disease. ${ }^{2}$ In this context, optimisation of risk prediction has emerged as an important clinical problem in this patient population, as it could assist with tailoring of preventive recommendations for management of lipids and blood pressure, and primary prevention with antiplatelet agents.

Computed tomography for measurement of calcium in the coronary arteries has been evaluated as a new non-invasive screening tool for predicting cardiovascular events. The coronary artery calcium score, which infers the presence of coronary atherosclerosis by measuring the amount of calcium in the coronary arteries, has been shown to predict the risk for cardiovascular events in large prospective studies. ${ }^{3-5}$ It also has been shown to add predictive value to existing global risk scores; in particular, the coronary artery calcium score helps to reclassify people at intermediate risk to either low or high risk groups. ${ }^{6-8}$ However, some of these large prospective studies excluded people with type 2 diabetes from the primary analysis, ${ }^{67}$ possibly because the condition itself confers an increased risk for cardiovascular events and hence is perceived as a unique patient population for prediction models. ${ }^{9}$

Although type 2 diabetes is associated with an overall increased risk of cardiovascular disease, considerable heterogeneity exists in vascular risk within the population of people with diabetes. ${ }^{10} 11$ For example, whereas a study of patients with type 2 diabetes and proteinuria reported an annual mortality rate of $5.4 \%,{ }^{12}$ the annual death rate in a non-selected population with type 2 diabetes has been reported to be more than four times lower, at $1.21 \% .{ }^{13}$ In addition, a study reported that a significant proportion (about 24\%) of people with type 2 diabetes had coronary artery calcium scores of $<10$, a threshold that has been associated with low risk of cardiovascular events. ${ }^{514}$ Thus, given the broad range of cardiovascular risk observed in people with type 2 diabetes and its implications for targeted preventive strategies in clinical practice, this population warrants focused investigation for the predictive value of the coronary artery calcium score. We systematically reviewed and meta-analysed prospective observational studies to evaluate the association of coronary artery calcium score with all cause mortality and cardiovascular events (fatal and non-fatal) in people with type 2 diabetes.

\section{Methods}

\section{Data sources and searches}

We undertook a systematic review of the published literature. We selected relevant studies published between 1950 and 13 February 2013 by searching Embase, PubMed, and abstracts from the 2011 and 2012 annual meetings of the American Diabetes Association, the European Association for the Study of Diabetes, the American College of Cardiology, and the American Heart Association (2011 annual meeting). The following combined text and medical subject heading terms were used: "coronary artery calcium" and "type 2 diabetes mellitus". The complete search used for PubMed was: Calcium score [text] OR coronary artery calcification [text] OR coronary artery calcium [text]) AND (“Diabetes Mellitus”[Mesh] OR “Diabetes Mellitus, Type 2"[Mesh]. All potentially eligible studies were considered for review, regardless of the primary outcome or language. A manual search was also performed, using references of key articles published in English. This systematic review and meta-analysis is reported in accordance with the meta-analysis of observational studies in epidemiology guidelines ${ }^{15}$ and is registered at International Prospective Register of Systematic Reviews (PROSPERO, www.crd.york. ac.uk/prospero/ CRD42012002915). The researchers are experienced in systematic reviews and meta-analysis. ${ }^{16-23}$

\section{Study selection}

Studies were considered eligible for inclusion if they were conducted in adults aged 18 years or older with type 2 diabetes, presented original data of prospective observational studies, evaluated the presence of coronary artery calcium score at baseline, and reported all cause mortality or fatal or non-fatal cardiovascular events. We defined fatal and non-fatal cardiovascular events as death due to cardiovascular disease or one of the following: myocardial infarction, acute coronary syndrome, admission to hospital for unstable angina or coronary catheterisation that resulted in angioplasty or coronary artery bypass surgery, congestive heart failure, and stroke or transient ischaemic attack. We compared the number of events in patients with a total coronary artery calcium score of $\geq 10$ (exposed group) with the number of events in patients with a total coronary artery calcium score of $<10$ (control group). These thresholds enabled inclusion of the maximum number of studies. Sensitivity analyses evaluating other thresholds for coronary artery calcium score were also performed. We excluded retrospective studies, studies that did not provide any source of absolute number of events in each group, and further publications of included studies.

\section{Data extraction and quality assessment}

Two independent investigators (CKK and TCR) reviewed study titles and abstracts. Studies that satisfied the inclusion criteria were retrieved for full text evaluation. Studies selected for detailed analysis by these two investigators had an agreement value ( $\kappa)$ of $97 \%$; disagreements were resolved by a third investigator (JLG or RR).

Extracted data included the clinical characteristics of participants, study design, duration of follow-up, and the number of participants who had an event, according to coronary artery calcium score status. We used numerical data in the articles. In the few studies not reporting these data, we calculated risk estimates from the survival curves. We emailed the authors of studies with appropriate data but with specific missing information, but none responded.

To assess the quality of the non-randomised studies included in the meta-analysis we applied the Newcastle-Ottawa scale. ${ }^{24}$ This scale contains eight items, categorised into the three domains of selection, comparability, and exposure. A series of response options is provided for each item. A star system is used to enable semiquantitative assessment of study quality, such that the highest quality studies are awarded a maximum of one star for each item, with the exception of the comparability domain, which allows the assignment of two stars. As such, the Newcastle-Ottawa scale ranges between zero and nine stars. ${ }^{25}$ 


\section{Data synthesis and analysis}

To assess the predictive value of the coronary artery calcium score for all cause mortality or cardiovascular events, or both, we calculated an overall relative risk. We compared people with a total coronary artery calcium score of $\geq 10$ with those with a total score of $<10$. In addition we carried out sensitivity analyses for other thresholds of scores. All analyses were done for outcomes of all cause mortality or cardiovascular events (fatal and non-fatal), or both, and of only cardiovascular events (fatal and non-fatal).

To adequately account for the additional uncertainty associated with study-study variability, we calculated pooled estimates of the relative risk by using a random effects model

(DerSimonian-Laird method). The Cochran Q test was used to evaluate heterogeneity between studies and we considered a threshold $\mathrm{P}$ value less than 0.1 as statistically significant. $\mathrm{I}^{2}$ testing was also performed to evaluate the magnitude of the heterogeneity between studies, and we considered values greater than $50 \%$ indicative of high heterogeneity. ${ }^{26}$

We explored heterogeneity between studies using three strategies. Firstly, we re-ran the meta-analysis removing studies one at a time to determine whether a particular study accounted for the heterogeneity. Secondly, we carried out stepwise metaregression analyses. Using random effects univariate metaregression models, we assessed several clinical and methodological variables that could influence the association of the coronary artery calcium score and the outcomes: duration of follow-up, age, proportion of males, proportion of participants with hypertension, proportion of smokers, baseline low density lipoprotein cholesterol level, and body mass index. Thereafter, based on univariate metaregression, we constructed a model including baseline low density lipoprotein cholesterol level, proportion of males, and proportion of participants with hypertension. To evaluate the goodness of fit of the model, we used the adjusted $\mathrm{R}^{2}$, which denotes the proportion of variation between studies explained by the covariates. Finally, we performed sensitivity analyses to evaluate subgroups of studies most likely to yield valid estimates.

To obtain the pooled estimates of sensitivity and specificity of the coronary artery calcium score for the development of outcomes, we constructed hierarchical summary receiver operating characteristic curves. We obtained the average likelihood ratios of the positive and negative test result. For practical clinical purposes, we estimated the post-test probability of the outcome using the Bayes normogram, considering the pretest probability as the incidence of the events in the included population. $^{27}$

The possibility of publication bias was evaluated using a funnel plot of effect size against the standard error for each trial. We used Begg's and Egger's tests to evaluate funnel plot asymmetry, with significant publication bias defined as a $\mathrm{P}$ value $<0.1{ }^{28}$ To estimate the effect of publication bias, we used the trim and fill computation. $^{29}$

All statistical analyses were performed using Stata 11.0 software.

\section{Results}

We identified 448 studies through electronic searches and two through manual searches (fig $1 \Downarrow$ ), all of which were published in English. Of these, 432 were excluded on the basis of the title and abstract, leaving 18 studies for further evaluation. Eight studies fulfilled our inclusion criteria, providing data on 6521 participants. $^{12-34}$
Table $1 \Downarrow$ summarises the included studies. The studies were published from 2004 to 2012 and varied in sample size. The mean duration of follow-up varied from 2.2 to 7.4 years; the proportion of loss to follow-up varied from $0 \%$ to $3 \%$. At baseline, the proportion of males ranged from $46 \%$ to $63.3 \%$, current smokers from $9 \%$ to $19 \%$, and participants with hypertension from $63.2 \%$ to $100 \%$. Seven studies measured the coronary artery calcium score using electron beam computed tomography (100 ms scan time) $)^{12-34}$ and one study used helical computed tomography (500 ms temporal resolution). ${ }^{32}$ These techniques have a reported accuracy of $84 \%^{35}$ and $76 \%,{ }^{36}$ respectively. Four studies evaluated all cause mortality as the outcome and four evaluated only cardiovascular events. Overall, 802 events (all cause mortality with fatal and non-fatal cardiovascular events) were reported, such that the overall incidence of events in the included population was $12.3 \%$ during a mean follow-up of 5.18 years.

Table $2 \Downarrow$ shows an evaluation of the included studies for possible bias. In accordance with the Newcastle-Ottawa quality assessment scale for cohort studies, all studies achieved at least seven stars, indicative of overall good quality.

\section{All cause mortality and cardiovascular events}

Eight studies ( $\mathrm{n}=6521)$ were included in this analysis. Overall, the prevalence of participants with a coronary artery calcium score of $<10$ was $28.5 \%$. The relative risk for all cause mortality or cardiovascular events, or both comparing a total coronary artery calcium score of $\geq 10$ with a score of $<10$ was $5.47(95 \%$ confidence interval 2.59 to 11.53 , fig $2 \Downarrow$ ). All but two studies reported a significant increase in the risk of this composite outcome. However, significant heterogeneity was evident among the individual estimates when the magnitude of the association was evaluated $\left(\mathrm{I}^{2}=82.4 \%, \mathrm{P}<0.001\right)$. Evidence of publication bias was lacking on Egger's regression test and the trim and fill computation ( $\mathrm{P}=0.77$, fig $3 \Downarrow$ ).

The overall sensitivity of a total coronary artery calcium score of $\geq 10$ for the composite outcome was $94 \%$ ( $95 \%$ confidence interval $89 \%$ to $96 \%)$, whereas the specificity was $34 \%(24 \%$ to $44 \%$, fig $4 \Downarrow$ ). The positive and negative likelihood ratios for all cause mortality or cardiovascular events, or both were 1.41 ( $95 \%$ confidence interval 1.20 to 1.66 ) and 0.18 (0.10 to 0.30 ), respectively. For participants with a coronary artery calcium score of $\geq 10$, the post-test probability of the composite outcome was approximately $17 \%$, considering a pretest probability of $12.3 \%$. In contrast, the post-test probability of the composite outcome for people with a coronary artery calcium score of $<10$ was approximately $1.8 \%$, representing a 6.8 -fold reduction from the pretest probability (fig $5 \Downarrow$ ).

We re-ran the meta-analysis excluding studies one at a time to determine if a particular study was responsible for the high heterogeneity. No single study fully explained the heterogeneity; however, two studies ${ }^{1234}$ made a higher contribution to the between study variance. We then performed a metaregression analysis in an exploratory attempt to identify the sources of heterogeneity between studies. In univariate metaregression models, the covariates of duration of follow-up, baseline age, sex, proportion of current smokers, proportion of participants with hypertension, and low density lipoprotein cholesterol level did not explain the high heterogeneity between studies. We constructed a multivariate model using the covariates that had better model fit in the univariate metaregression analysis: sex, proportion of participants with hypertension, and baseline low density lipoprotein cholesterol level. This model did not explain the variance between studies $(\mathrm{P}=0.84)$. Considering all of these 
exploratory analyses together, we carried out a sensitivity analysis excluding the two studies that contributed highly to the between study variance. ${ }^{12}{ }^{34}$ In addition to being the studies that best explained the variance between studies when excluded from analysis, both evaluated a population of people with diabetes at increased risk for cardiovascular events compared with the other studies (one evaluated only patients with proteinuria $^{12}$ and the other people with hypertension ${ }^{34}$ ). In the pooled analysis of the remaining six studies, the relative risk for all cause mortality or cardiovascular events, or both comparing a total coronary artery calcium score of $\geq 10$ with a score of $<10$ was 8.00 (95\% confidence interval 4.3 to 15.0 ). This approach reduced the heterogeneity between the individual efficacy estimates $\left(I^{2}=62 \%, P=0.02\right)$, although the heterogeneity was not eliminated.

\section{Cardiovascular events (fatal and non-fatal)}

Four studies evaluated cardiovascular events as the outcome $(\mathrm{n}=1805)$. Overall, 351 cardiovascular events occurred during a mean follow-up of 4.8 years (incidence of $19 \%$ ). In the pooled analysis, the relative risk for cardiovascular events comparing a total coronary artery calcium score of $\geq 10$ with a score of $<10$ was 9.22 (95\% confidence interval 2.73 to 31.07 , fig 2 ). When the magnitude of the association was evaluated, heterogeneity among the individual estimates was significant $\left(\mathrm{I}^{2}=76.7 \%\right.$, $\mathrm{P}=0.005)$. Evidence of publication bias was lacking on Egger's regression test and the trim and fill computation $(\mathrm{P}=0.65$, fig 3).

The overall sensitivity of a total coronary artery calcium score of $\geq 10$ for the cardiovascular outcome was $95 \%$ (95\% confidence interval $88 \%$ to $97 \%$ ) and the specificity was $43 \%$ ( $30 \%$ to $57 \%$, fig 4 ). The positive and negative likelihood ratios for cardiovascular events were 1.67 (95\% confidence interval 1.30 to 2.17 ) and 0.11 (0.04 to 0.29$)$, respectively. The post-test probability of this outcome for participants with a coronary artery calcium score of $\geq 10$ was approximately $23 \%$, considering a pretest probability of $19 \%$. The post-test probability of cardiovascular events for participants with a coronary artery calcium score of $<10$ was noticeably reduced at $2.5 \%$, representing a 7.6-fold reduction from the pretest probability (fig 5).

We further explored the heterogeneity between studies, performing the steps described earlier. Firstly, we re-ran the meta-analysis excluding studies one at a time to determine whether a particular study was responsible for the heterogeneity. One study ${ }^{34}$ fully explained the high heterogeneity. In univariate metaregression models, the covariates of duration of follow-up, baseline age, sex, proportion of current smokers, proportion of participants with hypertension, and low density lipoprotein cholesterol level did not explain the high heterogeneity between studies. We constructed a multivariate model using the two covariates that had better model fit in univariate metaregression analysis: sex and proportion of participants with hypertension (the number of studies included in the cardiovascular events meta-analysis precluded the evaluation of more than two covariates in the model). This model did not explain the variance between studies $(\mathrm{P}=0.79)$. Based on these exploratory analyses, we performed a sensitivity analysis excluding the study explaining the high heterogeneity. ${ }^{34}$ In the pooled analysis of the remaining three studies, the relative risk for cardiovascular events comparing a total coronary artery calcium score of $\geq 10$ with a score of $<10$ was 16.84 (95\% confidence interval 9.33 to 30.43$)$. This approach eliminated the heterogeneity $\left(\mathrm{I}^{2}=0 \%\right.$, $\mathrm{P}=0.68)$.

\section{Sensitivity analyses of other thresholds for coronary artery calcium score}

Table $3 \Downarrow$ shows the meta-analyses comparing the risk of all cause mortality or cardiovascular events, or both at different thresholds of coronary artery calcium score. Compared with a reference group with a coronary artery calcium score of $<10$, all thresholds of increased scores $(\geq 100, \geq 400$, and $\geq 1000)$ were associated with an increased risk for all cause mortality and cardiovascular events. As expected, the specificity of the coronary artery calcium score increased as the thresholds of the score increased. Of note, the negative likelihood ratio was about 0.1 . Furthermore, the same associations were observed when the reference group was considered as a coronary artery calcium score of $<100$, although the negative likelihood ratio was higher, at about 0.4 .

\section{Discussion}

In people with type 2 diabetes, the presence of a coronary artery calcium score of $\geq 10$ predicts both all cause mortality and cardiovascular events as well as cardiovascular events alone, with high sensitivity but low specificity. The negative likelihood ratio of the coronary artery calcium score for these outcomes was strikingly low ( 0.18 for all cause mortality and cardiovascular events, and 0.11 for cardiovascular events). Indeed, our evaluation of risk estimates through the Bayes normogram suggests that the coronary artery calcium score may be especially helpful in clinical practice when it is below 10 .

Our meta-analyses showed that the coronary artery calcium score might have a role in predicting events in people with type 2 diabetes. The findings of an increased relative risk for all cause mortality and cardiovascular events and cardiovascular events alone were consistent. The exploratory analysis of heterogeneity identified the variables associated with higher variance between studies, especially for cardiovascular events alone (where the sensitivity analysis eliminated the heterogeneity). We used the likelihood ratio as an alternative statistic because of its clinical applicability. Interestingly, we found a low negative likelihood ratio, in the range (that is, 0.1 ) that Deeks and Altman have previously suggested as providing strong evidence for ruling out the occurrence of an outcome in most circumstances. ${ }^{37}$

When evaluating a predictor of adverse outcomes, it is recognised that a useful predictor should have a favourable risk-benefit ratio, reasonable cost, acceptability, and convenience. In addition, to make screening worthwhile an effective treatment should be available, and this treatment should not be equally effective in everyone. ${ }^{38}$ In this context, screening using the coronary artery calcium score is a convenient and non-invasive test, although it involves exposure to ionising radiation of about 1 millisieverts (which is comparable to screening mammography).$^{39}$ No formal cost effectiveness analyses have been done on the coronary artery calcium score in people with type 2 diabetes integrating risk, benefits, and cost; however, the current findings raise the possibility that screening using the coronary artery calcium score may be cost effective in some subgroups of people with diabetes. Moreover, a previous report showed that patient awareness of an abnormal score was associated with increased adherence to aspirin use and lifestyle changes, ${ }^{40}$ suggesting that, besides risk stratification, the coronary artery calcium score might help to support behavioural modification.

The American Heart Association has supported the use of the coronary artery calcium score quantification in people at intermediate risk to improve risk assessment (class IIb recommendation). ${ }^{41}$ Conversely, the American Diabetes 
Association does not recommend its routine use in people with type 2 diabetes because the overall balance of risk, benefits, and cost of such an approach in people without symptoms remains controversial. ${ }^{1}$ In light of the lack of previous evidence to support the routine use of the coronary artery calcium score as a screening test in people with type 2 diabetes, we feel that the current meta-analysis is much needed and holds implications for the design of future studies. In particular, the finding of such a low likelihood ratio suggests that a coronary artery calcium score of $<10$ might help with risk stratification of people with type 2 diabetes and potentially would change prevention strategies in those people. In fact, it has been suggested that the coronary artery calcium score may help to identify people with diabetes who may benefit from aspirin therapy among those without a clear indication based on current guidelines. ${ }^{13}$ Most importantly, if we consider that the prevalence of a coronary artery calcium score of $<10$ was $28.5 \%$ in our study population, the current findings might have an important impact on clinical care. Indeed, considering the worldwide prevalence of 346 million cases of type 2 diabetes, ${ }^{42}$ these data suggest that about 86.5 million people with type 2 diabetes would have a coronary artery calcium score of $<10$ and hence a low risk of cardiovascular events. In addition, a score of $<10$ has been observed in a significant proportion of people with diabetes at intermediate risk on pretest assessment, a subgroup of people who would most benefit from the coronary artery calcium score test. ${ }^{13}{ }^{33}$ In this way, screening using the coronary artery calcium score may facilitate clinical risk stratification by identifying a sizeable subgroup of people at low risk within the high risk population of people with diabetes.

The concept of a low risk subgroup within the population of people with diabetes has been demonstrated in a previous report that showed a similar risk of all cause mortality between people with and without diabetes who had no coronary artery calcium score at baseline (survival $98.8 \% v 99.4 \%$ over five years, $\mathrm{P}=0.49) .{ }^{30}$ These data reinforce the results of our meta-analysis, in which a coronary artery calcium score of $<10$ was indicative of low risk for future events in people with diabetes. In addition, in the same way that the coronary artery calcium score adds to current predictive scores in the general population, ${ }^{6}$ these data raise the possibility that incorporation of coronary artery calcium score into existing risk scores for people with diabetes might improve risk prediction and hence warrants further investigation.

\section{Limitations of this review}

A limitation of our meta-analysis is that an analysis of additional risk stratification beyond current available risk scores for people with type 2 diabetes could not be performed owing to the absence of such studies. Secondly, most studies did not take into consideration the use of drugs (that is, aspirin and lipid lowering drugs) that could interfere with the estimates of event rate prediction based on the coronary artery calcium score. Nevertheless, as all studies were performed after 2004, we believe that the people were possibly treated similarly based on current clinical practice recommendations. Thirdly, only three studies reported baseline glycated haemoglobin $\mathrm{A}_{\mathrm{lc}}$ and duration of diabetes. However, although these covariates could not be included in metaregression analyses, our models were able to identify the studies that better explained the variance between studies. Of note, although most studies measured the coronary artery calcium score using the same technique, differences in the protocol for obtaining the scores could also have contributed to the variance between studies. Finally, we recognise that publication bias and the quality limitations of individual studies may still be relevant despite our best efforts to conduct a comprehensive search and the lack of statistical evidence of bias. The subjective nature of the Newcastle-Ottawa scale by which the quality of studies was assessed should also be noted.

Our meta-analysis strongly suggests that the coronary artery calcium score warrants further investigation as a prediction tool in people with type 2 diabetes. In particular, randomised controlled trials evaluating the impact of screening using the coronary artery calcium score on mortality are needed. Another point to consider in future studies is that atherosclerosis is a dynamic process, as shown by studies documenting both progression and regression of plaque. ${ }^{43-45}$ Glucose levels are an independent risk factor for progression of coronary artery calcium score, ${ }^{46}$ and people with type 2 diabetes have been shown to have a higher rate of progression than those without diabetes. ${ }^{47}$ Thus, the optimal frequency of screening using the coronary artery calcium score also needs to be established.

\section{Conclusion}

The coronary artery calcium score predicts all cause mortality and cardiovascular events and cardiovascular events alone in people with type 2 diabetes. People with a coronary artery calcium score of $<10$ were 6.8 times less likely to have cardiovascular event. Taken together, our meta-analysis strongly suggests the need for further investigation of the utility of using the coronary artery calcium score, particularly because of the implications that a negative screening test may hold for clinical risk stratification and preventive management in this population.

Contributors: RR had full access to all of the data in the study and takes responsibility for the integrity of the data and the accuracy of the data analysis. RR is the guarantor. CKK and RR conceived and designed the study. CKK, TCR, and RR acquired the data. CKK did the statistical analysis. All authors analysed and interpreted the data and critically revised the manuscript for important intellectual content. CKK drafted the manuscript. BZ, JLG, and RR supervised the study.

Funding: CKK holds a Canadian Diabetes Association postdoctoral fellowship award. BZ holds the Sam and Judy Pencer family chair in diabetes research at Mount Sinai Hospital and the University of Toronto. RR holds an Ontario Ministry of Research and Innovation early researcher award. The study was supported by intramural funds from the Leadership Sinai Centre for Diabetes. The funding source had no role in the study design, data collection, data analysis, data interpretation, or writing of the report.

Competing interests: All authors have completed the ICMJE uniform disclosure form at www.icmje.org/coi_disclosure.pdf (available on request from the corresponding author) and declare: no support from any organisation for the submitted work; BZ has served as a consultant for Merck, Boehringer Ingelheim, Novo Nordisk, and Eli Lilly, received grants from Merck, Boehringer Ingelheim, and Novo Nordisk, and received payment for lectures for Merck and Novo Nordisk; JLG has served on boards for Bristol-Myers Squibb, GlaxoSmithKline, Novo Nordisk, Sanofi-Aventis, and Eli Lilly, and has received payment for the development of educational presentations for Bristol-Myers Squibb, Novo Nordisk, and Eli Lilly; LHC has served on a board for Janssen Cilag; RR has served as a consultant for Merck and Novo Nordisk, received grants from Merck and Novo Nordisk, and received payment for lectures for Eli Lilly; no other relationships or activities that could appear to have influenced the submitted work.

Ethical approval: Not required.

Data sharing: Additional data and statistical codes are available on request from the corresponding author at rretnakaran@mtsinai.on.ca.

Standards of medical care in diabetes-2012. Diabetes Care 2012;35(Suppl 1):S11-63. Rana JS, Dunning A, Achenbach S, Al-Mallah M, Budoff MJ, Cademartiri F, et al. Differences in prevalence, extent, severity, and prognosis of coronary artery disease 


\section{What is already known on this topic}

The coronary artery calcium (CAC) score has been shown to predict the risk for cardiovascular events and facilitate reclassification of people from intermediate to low or high risk in large prospective studies of the general population However, most of these studies excluded people with diabetes

The role of the CAC score in people with type 2 diabetes is unclear and given the broad range of cardiovascular risk observed in people with diabetes, this population warrants focused investigation on the predictive capacity of the CAC score

\section{What this study adds}

A CAC score of $\geq 10$ predicted all cause mortality or cardiovascular events, or both compared with a score of $<10$, with high sensitivity but low specificity

For people with a CAC score of $<10$, the post-test probability of all cause mortality or cardiovascular events was reduced by 6.8 -fold from their pretest probability

In people with diabetes, the finding of a CAC score of $<10$ may facilitate risk stratification by enabling the identification of low risk people within this otherwise high risk population

among patients with and without diabetes undergoing coronary computed tomography angiography: results from 10,110 individuals from the CONFIRM (COronary CT Angiography EvaluatioN For Clinical Outcomes): an InteRnational Multicenter Registry. Diabetes Care 2012;35:1787-94.

3 Raggi P, Gongora MC, Gopal A, Callister TQ, Budoff M, Shaw LJ. Coronary artery calcium to predict all-cause mortality in elderly men and women. J Am Coll Cardiol 2008:52:17-23.

4 Greenland P, LaBree L, Azen SP, Doherty TM, Detrano RC. Coronary artery calcium score combined with Framingham score for risk prediction in asymptomatic individuals. JAMA 2004;291:210-5.

5 Detrano R, Guerci AD, Carr JJ, Bild DE, Burke G, Folsom AR, et al. Coronary calcium as a predictor of coronary events in four racial or ethnic groups. N Engl J Med 2008;358:1336-45.

6 Polonsky TS, McClelland RL, Jorgensen NW, Bild DE, Burke GL, Guerci AD, et al. Coronary artery calcium score and risk classification for coronary heart disease prediction. JAMA 2010;303:1610-6.

7 Yeboah J, McClelland RL, Polonsky TS, Burke GL, Sibley CT, O'Leary D, et al. Comparison of novel risk markers for improvement in cardiovascular risk assessment in intermediate-risk individuals. JAMA 2012;308:788-95.

8 Kavousi M, Elias-Smale S, Rutten JH, Leening MJ, Vliegenthart R, Verwoert GC, et al. Evaluation of newer risk markers for coronary heart disease risk classification: a cohort study. Ann Intern Med 2012;156:438-44.

9 Coleman RL, Stevens RJ, Retnakaran R, Holman RR. Framingham, SCORE, and DECODE risk equations do not provide reliable cardiovascular risk estimates in type 2 diabetes. Diabetes Care 2007:30:1292-3.

10 Dora JM, Kramer CK, Canani LH. Standards of medical care in diabetes-2008: response to Hirsch, Inzucchi, and Kirkman. Diabetes Care 2008;31:e44; author reply e45.

11 Stevens RJ, Kothari V, Adler AI, Stratton IM. The UKPDS risk engine: a model for the risk of coronary heart disease in type II diabetes (UKPDS 56). Clin Sci (Lond) 2001;101:671-9.

12 Chiu YW, Adler SG, Budoff MJ, Takasu J, Ashai J, Mehrotra R. Coronary artery calcification and mortality in diabetic patients with proteinuria. Kidney Int 2010;77:1107-14.

13 Silverman MG, Blaha MJ, Budoff MJ, Rivera JJ, Raggi P, Shaw LJ, et al. Potential implications of coronary artery calcium testing for guiding aspirin use among asymptomatic individuals with diabetes. Diabetes Care 2012;35:624-6.

14 Elkeles RS, Godsland IF, Feher MD, Rubens MB, Roughton M, Nugara F, et al. Coronary calcium measurement improves prediction of cardiovascular events in asymptomatic patients with type 2 diabetes: the PREDICT study. Eur Heart J 2008;29:2244-51.

15 Stroup DF, Berlin JA, Morton SC, Olkin I, Williamson GD, Rennie D, et al. Meta-analysis of observational studies in epidemiology: a proposal for reporting. Meta-analysis Of Observational Studies in Epidemiology (MOOSE) group. JAMA 2000;283:2008-12.

16 Kramer CK, Zinman B, Retnakaran R.Short-term intensive insulin therapy and its impact on type 2 diabetes: a systematic review and meta-analysis. Lancet Diabetes Endocrinol 2013; published online 30 January.

17 Umpierre D, Ribeiro PA, Kramer CK, Leitao CB, Zucatti AT, Azevedo MJ, et al. Physical activity advice only or structured exercise training and association with $\mathrm{HbA} 1 \mathrm{c}$ levels in type 2 diabetes: a systematic review and meta-analysis. JAMA 2011;305:1790-9.

18 Gross JL, Kramer CK, Leitao CB, Hawkins N, Viana LV, Schaan BD, et al. Effect of antihyperglycemic agents added to metformin and a sulfonylurea on glycemic control and weight gain in type 2 diabetes: a network meta-analysis. Ann Intern Med 2011;154:672-9.

19 Kramer CK, Rodrigues TC, Canani LH, Gross JL, Azevedo MJ. Diabetic retinopathy predicts all-cause mortality and cardiovascular events in both type 1 and 2 diabetes: meta-analysis of observational studies. Diabetes Care 2011;34:1238-44

20 Kramer CK, Leitao CB, Pinto LC, Canani LH, Azevedo MJ, Gross JL. Efficacy and safety of topiramate on weight loss: a meta-analysis of randomized controlled trials. Obes Rev 2011;12:e338-47.

21 Gilbert J, Raboud J, Zinman B. Meta-analysis of the effect of diabetes on restenosis rates among patients receiving coronary angioplasty stenting. Diabetes Care 2004;27:990-4.

22 Retnakaran R, Hochman J, DeVries JH, Hanaire-Broutin H, Heine RJ, Melki V, et al. Continuous subcutaneous insulin infusion versus multiple daily injections: the impact of baseline A1c. Diabetes Care 2004;27:2590-6.

23 Lee WL, Cheung AM, Cape D, Zinman B. Impact of diabetes on coronary artery disease in women and men: a meta-analysis of prospective studies. Diabetes Care 2000;23:962-8.

24 Wells GA, Shea B, O'Connell D, Peterson J, Welch V, Losos M. The Newcastle-Ottawa Scale (NOS) for assessing the quality of nonrandomised studies in meta-analyses [Internet]. Ottawa Hospital Research Institute. 2012. www.ohri.ca/programs/clinical_ epidemiology/oxford.asp.

25 Stang A. Critical evaluation of the Newcastle-Ottawa scale for the assessment of the quality of nonrandomized studies in meta-analyses. Eur J Epidemiol 2010;25:603-5.
26 Higgins JP, Thompson SG. Quantifying heterogeneity in a meta-analysis. Stat Med 2002;21:1539-58

27 Fagan TJ. Letter: normogram for Bayes theorem. N Engl J Med 1975;293:257.

28 Begg CB, Mazumdar M. Operating characteristics of a rank correlation test for publication bias. Biometrics 1994;50:1088-101.

29 Duval S, Tweedie R. Trim and fill: a simple funnel-plot-based method of testing and adjusting for publication bias in meta-analysis. Biometrics 2000;56:455-63.

30 Raggi P, Shaw LJ, Berman DS, Callister TQ. Prognostic value of coronary artery calcium screening in subjects with and without diabetes. J Am Coll Cardiol 2004;43:1663-9.

31 Anand DV, Lim E, Hopkins D, Corder R, Shaw LJ, Sharp P, et al. Risk stratification in uncomplicated type 2 diabetes: prospective evaluation of the combined use of coronary artery calcium imaging and selective myocardial perfusion scintigraphy. Eur Heart $J$ 2006:27:713-21.

32 Agarwal S, Morgan T, Herrington DM, Xu J, Cox AJ, Freedman BI, et al. Coronary calcium score and prediction of all-cause mortality in diabetes: the diabetes heart study. Diabetes Care 2011;34:1219-24.

33 Malik S, Budoff MJ, Katz R, Blumenthal RS, Bertoni AG, Nasir K, et al. Impact of subclinical atherosclerosis on cardiovascular disease events in individuals with metabolic syndrome and diabetes: the multi-ethnic study of atherosclerosis. Diabetes Care 2011;34:2285-90.

34 Shemesh J, Motro M, Morag-Koren N, Konen E, Grossman E. Relation of coronary artery calcium to cardiovascular risk in patients with combined diabetes mellitus and systemic hypertension. Am J Cardiol 2012;109:844-50.

35 Shemesh J, Apter S, Rozenman J, Lusky A, Rath S, Itzchak Y, et al. Calcification of coronary arteries: detection and quantification with double-helix CT. Radiology 1995:197:779-83.

36 Broderick LS, Shemesh J, Wilensky RL, Eckert GJ, Zhou X, Torres WE, et al. Measurement of coronary artery calcium with dual-slice helical CT compared with coronary angiography: evaluation of CT scoring methods, interobserver variations, and reproducibility. AJR Am $J$ Roentgenol 1996;167:439-44.

37 Deeks JJ, Altman DG. Diagnostic tests 4: likelihood ratios. BMJ 2004:329:168-9.

38 Ioannidis JP, Tzoulaki I. What makes a good predictor?: the evidence applied to coronary artery calcium score. JAMA 2010;303:1646-7.

39 Einstein AJ. Medical imaging: the radiation issue. Nat Rev Cardiol 2009;6:436-8.

40 Orakzai RH, Nasir K, Orakzai SH, Kalia N, Gopal A, Musunuru K, et al. Effect of patient visualization of coronary calcium by electron beam computed tomography on changes in beneficial lifestyle behaviors. Am J Cardiol 2008:101:999-1002.

41 O'Rourke RA, Brundage BH, Froelicher VF, Greenland P, Grundy SM, Hachamovitch R, et al. American College of Cardiology/American Heart Association Expert Consensus Document on electron-beam computed tomography for the diagnosis and prognosis of coronary artery disease. J Am Coll Cardiol 2000;36:326-40.

42 World Health Organization. 2012. www.who.int/diabetes/en/index.html.

43 McEvoy JW, Blaha MJ, Defilippis AP, Budoff MJ, Nasir K, Blumenthal RS, et al. Coronary artery calcium progression: an important clinical measurement? A review of published reports. J Am Coll Cardiol 2010;56:1613-22.

44 Jassal SK, Chonchol M, Laughlin GA, Cummins KM, Smits G, Kramer CK, et al. Kidney function and progression of coronary artery calcium in community-dwelling older adults (from the Rancho Bernardo Study). Am J Cardiol 2012;110:1425-33.

45 Kramer CK, von Muhlen D, Gross JL, Barrett-Connor E. A prospective study of abdomina obesity and coronary artery calcium progression in older adults. J Clin Endocrinol Metab 2009:94:5039-44.

46 Kramer CK, von Muhlen D, Gross JL, Laughlin GA, Barrett-Connor E. Blood pressure and fasting plasma glucose rather than metabolic syndrome predict coronary artery calcium progression: the Rancho Bernardo Study. Diabetes Care 2009:32:141-6.

47 Raggi P, Cooil B, Ratti C, Callister TQ, Budoff M. Progression of coronary artery calcium and occurrence of myocardial infarction in patients with and without diabetes mellitus. Hypertension 2005;46:238-43.

\section{Accepted: 26 February 2013}

\section{Cite this as: BMJ 2013;346:f1654}

This is an open-access article distributed under the terms of the Creative Commons Attribution Non-commercial License, which permits use, distribution, and reproduction in any medium, provided the original work is properly cited, the use is non commercial and is otherwise in compliance with the license. See: http://creativecommons.org/licenses/bync/2.0/ and http://creativecommons.org/licenses/by-nc/2.0/legalcode. 


\section{Tables}

\begin{tabular}{|c|c|c|c|c|c|c|c|c|c|c|}
\hline \multicolumn{11}{|c|}{ Table 1/ Characteristics of included studies } \\
\hline \multirow[b]{2}{*}{ Study } & \multirow[b]{2}{*}{$\begin{array}{l}\text { Population } \\
\text { studied (No) }\end{array}$} & \multirow{2}{*}{$\begin{array}{l}\text { Mean } \\
\text { follow-up } \\
\text { (years) }\end{array}$} & \multirow{2}{*}{$\begin{array}{l}\text { Loss of } \\
\text { follow-up } \\
\text { (\%) }\end{array}$} & \multirow[b]{2}{*}{ Event } & \multirow{2}{*}{$\begin{array}{l}\text { Mean } \\
\text { age } \\
\text { (years) }\end{array}$} & \multicolumn{3}{|c|}{ Proportion (\%) } & \multirow{2}{*}{$\begin{array}{c}\text { HDL } \\
\text { cholesterol } \\
\text { (mg/dL) }\end{array}$} & \multirow{2}{*}{$\begin{array}{c}\text { LDL } \\
\text { cholesterol } \\
\text { (mg/dL) }\end{array}$} \\
\hline & & & & & & Males & $\begin{array}{l}\text { Current } \\
\text { smokers }\end{array}$ & Hypertensive & & \\
\hline $\begin{array}{l}\text { Raggi } \\
2004^{30} \\
\end{array}$ & $\begin{array}{l}\text { Type } 2 \text { diabetes } \\
(903)\end{array}$ & 3.5 & $0^{*}$ & All cause mortality & 57 & 57 & $\mathrm{n} / \mathrm{a}$ & 63.2 & NA & NA \\
\hline $\begin{array}{l}\text { Anand } \\
2006^{31}\end{array}$ & $\begin{array}{l}\text { Type } 2 \text { diabetes } \\
\text { (181) }\end{array}$ & 2.2 & 0.2 & $\begin{array}{l}\text { Cardiovascular death, } \\
\text { myocardial infarction, acute } \\
\text { coronary syndrome, and } \\
\text { revascularisation or } \\
\text { non-haemorrhagic stroke }\end{array}$ & 52.7 & 60.6 & 19 & 74.5 & 49 & 105.6 \\
\hline $\begin{array}{l}\text { Elkeles } \\
2008^{14}\end{array}$ & $\begin{array}{l}\text { Type } 2 \text { diabetes } \\
\text { (589) }\end{array}$ & 4 & $\begin{array}{l}\text { Not } \\
\text { reported }\end{array}$ & $\begin{array}{l}\text { Cardiovascular death, } \\
\text { myocardial infarction, acute } \\
\text { coronary syndrome, or stroke }\end{array}$ & 63.1 & 63.3 & 15.1 & 63.3 & 43 & 104 \\
\hline Chiu $2010^{12}$ & $\begin{array}{l}\text { Proteinuria and } \\
\text { type } 2 \text { diabetes } \\
(225)\end{array}$ & 3.25 & $0^{*}$ & All cause mortality & 57 & 54 & 17 & NA & NA & 109 \\
\hline $\begin{array}{l}\text { Agarwal } \\
2011^{32}\end{array}$ & $\begin{array}{l}\text { Type } 2 \text { diabetes } \\
(1048)\end{array}$ & 7.4 & $0^{*}$ & All cause mortality & 61.7 & 46 & 17 & 88 & 44 & 104.5 \\
\hline Malik $2011^{33}$ & $\begin{array}{l}\text { Type } 2 \text { diabetes } \\
\text { (871) }\end{array}$ & 6.4 & 3 & $\begin{array}{l}\text { Myocardial infarction, angina, } \\
\text { resuscitated cardiac arrest, } \\
\text { coronary heart disease death, } \\
\text { stroke, and stroke death }\end{array}$ & 65 & 52 & 13 & 66 & 46 & 111 \\
\hline $\begin{array}{l}\text { Shemesh } \\
2012^{34}\end{array}$ & $\begin{array}{l}\text { Hypertension and } \\
\text { type } 2 \text { diabetes } \\
\text { (164) }\end{array}$ & 3 & 0 & $\begin{array}{l}\text { Sudden death; death from } \\
\text { coronary heart disease, } \\
\text { congestive heart failure, and } \\
\text { cerebrovascular disease; } \\
\text { myocardial infarction, } \\
\text { admission to hospital for } \\
\text { unstable angina or coronary } \\
\text { catheterisation that resulted in } \\
\text { angioplasty or coronary artery } \\
\text { bypass surgery, and stroke or } \\
\text { transient ischaemic attack }\end{array}$ & 64 & 52 & 9 & 100 & 42 & 151 \\
\hline $\begin{array}{l}\text { Silverman } \\
2012^{13}\end{array}$ & $\begin{array}{l}\text { Type } 2 \text { diabetes } \\
(2384)\end{array}$ & 5.6 & $0^{*}$ & All cause mortality & 58 & 52 & NA & NA & NA & NA \\
\hline
\end{tabular}

$N A=$ not available; $H D L=h i g h$ density lipoprotein; $L D L=l o w$ density lipoprotein.

*Vital status obtained through US national death index. 
Table 2| Newcastle-Ottawa quality assessment scale for cohort studies

\begin{tabular}{|c|c|c|c|}
\hline Study & Selection & Comparability & Outcome \\
\hline Raggi $2004^{30}$ & $* \star \star *$ & * & $\star \star * *$ \\
\hline Anand $2006^{31}$ & $* * *$ & * & ** \\
\hline Elkeles $2008^{14}$ & $* * *$ & * & ** \\
\hline Chiu $2010^{12}$ & $\star \star \star *$ & * & $* \star *$ \\
\hline Agarwal $2011^{32}$ & $* * *$ & * & $* * *$ \\
\hline Malik $2011^{33}$ & $* * * *$ & * & $* \star *$ \\
\hline Shemesh $2012^{34}$ & $* * *$ & * & $* * *$ \\
\hline Silverman $2012^{13}$ & 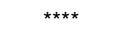 & * & $\star \star \star *$ \\
\hline
\end{tabular}

Scale ranges between zero and nine stars. Highest quality studies awarded maximum of one star for each item, with exception of comparability, which can have two stars. 
Table 3| Meta-analysis comparing risk of all cause mortality or cardiovascular events, or both at different thresholds of coronary artery calcium (CAC) score in people with type 2 diabetes

\begin{tabular}{|c|c|c|c|c|c|c|c|c|}
\hline $\begin{array}{l}\text { Thresholds of CAC score } \\
\text { evaluated }\end{array}$ & $\begin{array}{l}\text { No of } \\
\text { studies }\end{array}$ & $\begin{array}{c}\text { No of } \\
\text { participants } \\
\text { evaluated }\end{array}$ & $\begin{array}{l}\text { Relative risk }(95 \% \\
\text { Cl) }\end{array}$ & $I^{2}$ & $\begin{array}{l}\text { Sensitivity }(95 \% \\
\text { CI) }\end{array}$ & $\begin{array}{l}\text { Specificity }(95 \% \\
\text { CI) }\end{array}$ & $\begin{array}{l}\text { Positive likelihood } \\
\text { ratio }(95 \% \mathrm{Cl})\end{array}$ & $\begin{array}{l}\text { Negative likelihood } \\
\text { ratio }(95 \% \mathrm{Cl})\end{array}$ \\
\hline \multicolumn{9}{|l|}{$\begin{array}{l}\text { CAC score }<10 \text { as } \\
\text { reference group: }\end{array}$} \\
\hline Score $\geq 100 v<10$ & 6 & 3014 & 8.4 (2.9 to 24.4$)$ & 86.9 & 94 (88 to 97 ) & 43 (30 to 57$)$ & 1.7 (1.3 to 2.1$)$ & 0.1 (0.06 to 0.3$)$ \\
\hline Score $\geq 400 v<10$ & 5 & 1573 & 13.2 (3.3 to 53.8 ) & 89.3 & 90 (78 to 96$)$ & 70 (57 to 81$)$ & 3.0 (1.9 to 4.9$)$ & 0.1 (0.05 to 0.3$)$ \\
\hline Score $\geq 1000 v<10$ & 4 & 1261 & 13.8 (5.4 to 34.9$)$ & 52.9 & 90 (82 to 95 ) & 74 (50 to 89$)$ & 3.5 (1.6 to 7.6$)$ & 0.1 (0.07 to 0.2$)$ \\
\hline \multicolumn{9}{|l|}{$\begin{array}{l}\text { CAC score }<100 \text { as } \\
\text { reference group: }\end{array}$} \\
\hline Score $\geq 100 v<100$ & 7 & 6392 & 3.4 (2.4 to 4.8$)$ & 78.3 & 75 (67 to 82 ) & 58 (46 to 70$)$ & $1.8(1.4$ to 2.4$)$ & $0.4(0.3$ to 0.5$)$ \\
\hline Score $\geq 400 v<100$ & 5 & 2344 & 4.7 (2.5 to 9.0 ) & 88.1 & 63 (52 to 72 ) & 80 (66 to 90$)$ & 3.3 (1.7 to 6.3 ) & $0.4(0.3$ to 0.6$)$ \\
\hline Score $\geq 1000 v<100$ & 4 & 2757 & 7.3 (3.0 to 17.7$)$ & 87.2 & 66 (51 to 79$)$ & 85 (64 to 95 ) & $4.4(1.8$ to 10.1$)$ & $0.4(0.3$ to 0.6$)$ \\
\hline
\end{tabular}




\section{Figures}

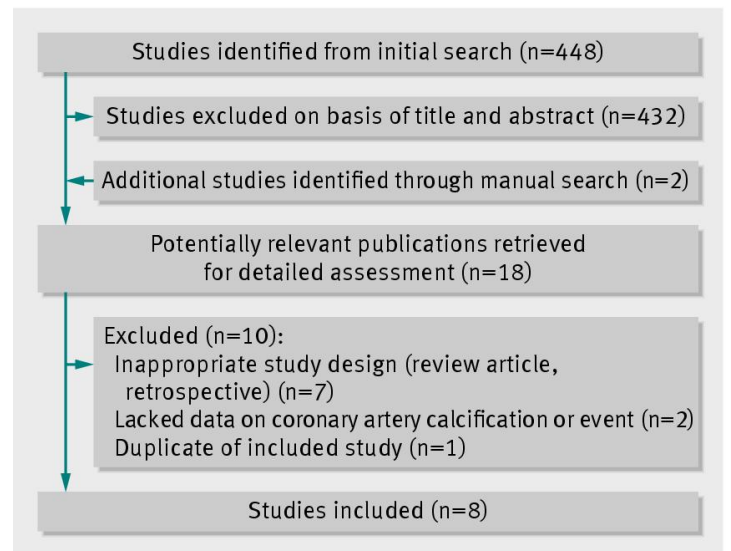

Fig 1 Flow diagram of literature search to identify observational studies on coronary artery calcium score and events in people with type 2 diabetes

\begin{tabular}{|c|c|c|c|c|}
\hline \multirow{2}{*}{\multicolumn{2}{|c|}{$\begin{array}{l}\text { Study } \\
\text { All cause mortality or cardiovascular } \\
\text { events (fatal and non-fatal), or both }\end{array}$}} & \multirow{2}{*}{$\begin{array}{l}\text { Relative risk } \\
\quad(95 \% \mathrm{Cl})\end{array}$} & \multirow{2}{*}{$\begin{array}{l}\text { Weight } \\
\text { (\%) }\end{array}$} & \multirow{2}{*}{$\begin{array}{l}\text { Relative risk } \\
\quad(95 \% \mathrm{Cl})\end{array}$} \\
\hline & & & & \\
\hline Raggi $2004^{30}$ & 903 & & 12.49 & 6.84 (2.48 to 18.88$)$ \\
\hline Anand $2006^{31}$ & 181 & & 7.55 & $24.15(3.31$ to 176.10$)$ \\
\hline Elkeles $2008^{14}$ & 589 & & 10.36 & 9.79 (2.43 to 39.49$)$ \\
\hline Chiu $2010^{12}$ & 225 & 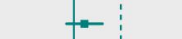 & 14.62 & $1.46(0.79$ to 2.70$)$ \\
\hline Agarwal $2011^{32}$ & 1048 & $\rightarrow$ & 14.03 & $3.86(1.85$ to 8.05$)$ \\
\hline Malik $2011^{33}$ & 871 & & 14.26 & $18.43(9.23$ to 36.78$)$ \\
\hline Shemesh $2012^{34}$ & 164 & 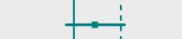 & 12.30 & $2.13(0.75$ to 6.07$)$ \\
\hline Silverman $2012^{13}$ & 2384 & & 14.39 & $4.92(2.53$ to 9.57$)$ \\
\hline Overall: $P<0.001, I^{2}$ & & & 100.00 & $5.47(2.59$ to 11.53$)$ \\
\hline \multicolumn{5}{|c|}{ Cardiovascular events (fatal and non-fatal) } \\
\hline Anand $2006^{31}$ & 181 & & 17.93 & $24.15(3.31$ to 176.10$)$ \\
\hline Elkeles $2008^{14}$ & 589 & & 23.69 & 9.79 (2.43 to 39.49$)$ \\
\hline Malik $2011^{33}$ & 871 & & 30.97 & $18.43(9.23$ to 36.78$)$ \\
\hline Shemesh $2012^{34}$ & 164 & & 27.41 & 2.13 (0.75 to 6.07$)$ \\
\hline \multirow[t]{2}{*}{ Overall: $P=0.005, I^{2}$} & & & 100.00 & $9.22(2.73$ to 31.07$)$ \\
\hline & 0.00568 & 1 & & \\
\hline
\end{tabular}

Fig 2 Meta-analyses of association between coronary artery calcium score $\geq 10$ and outcome in people with type 2 diabetes. Weights are from random effects analysis 


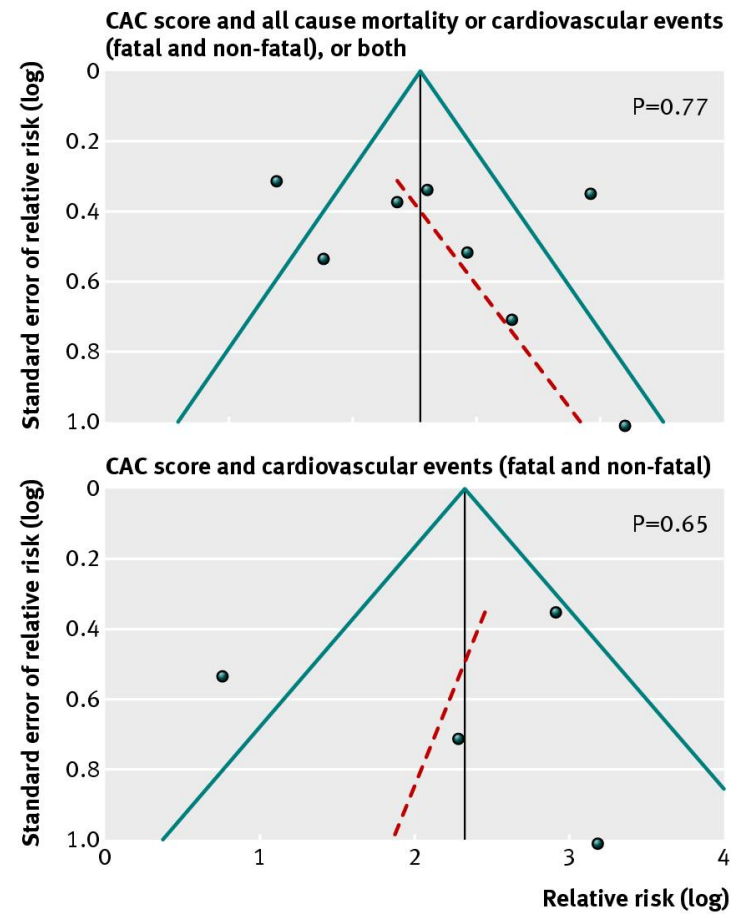

Fig 3 Funnel plots with Egger's regression line for coronary artery calcium (CAC) score and outcome 


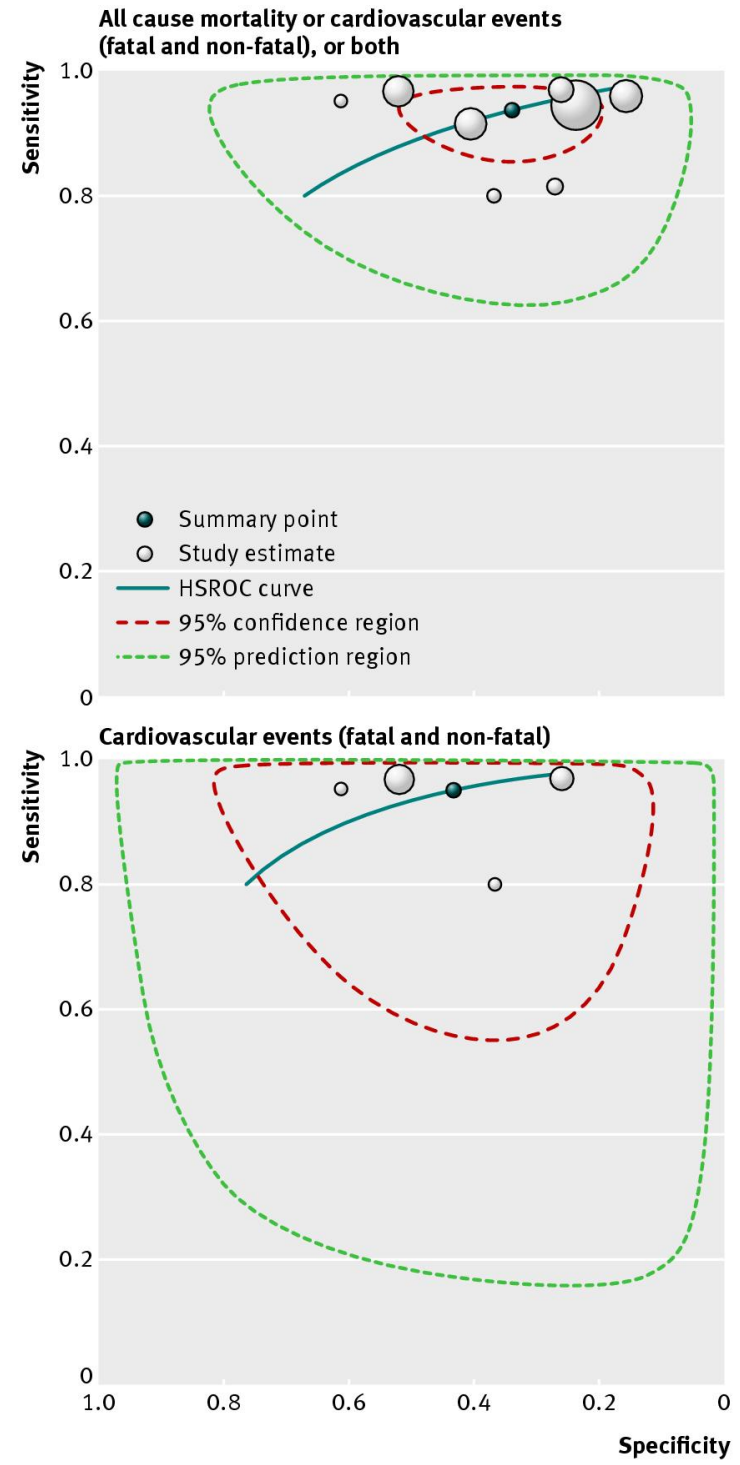

Fig 4 Hierarchical summary receiver operating characteristic (HSROC) curves of coronary artery calcium score $\geq 10$ and events in people with type 2 diabetes by outcome 


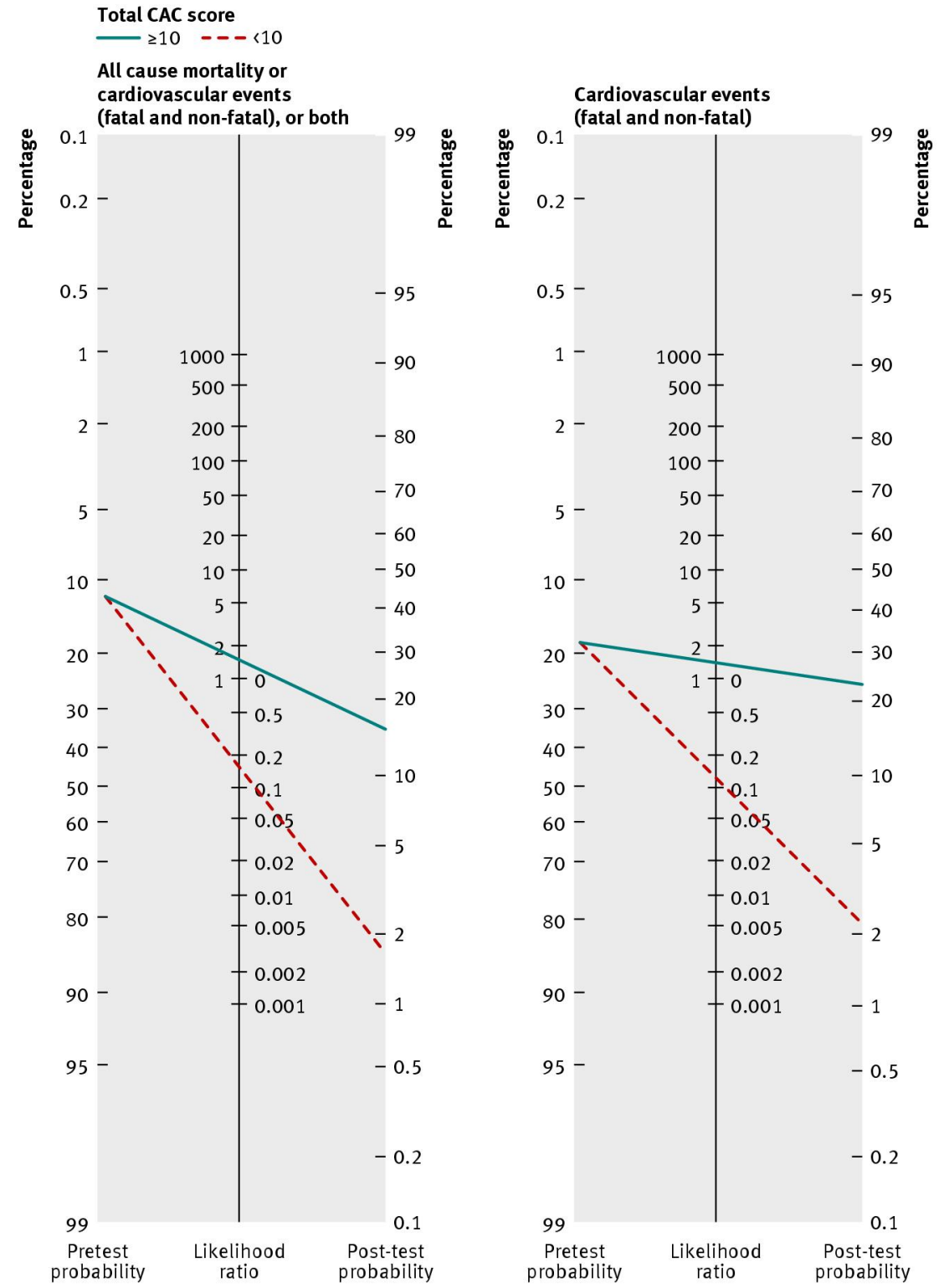

Fig 5 Bayes normogram for coronary artery calcium (CAC) score showing post-test probability of event in people with type 2 diabetes with total coronary artery calcium score $\geq 10$ and $<10$ by outcome 